Re-submitted to Spine, 21st December 2009

\title{
Mechanical function of vertebral body osteophytes, as revealed by experiments on cadaveric spines.
}

\author{
Maimouna Al-Rawahi* MB ChB, PhD, Jin Luo PhD, Phillip Pollintine ${ }^{+}$MSc PhD, \\ Patricia Dolan PhD, Michael A. Adams PhD \\ Department of Anatomy, University of Bristol, Bristol, UK \\ *Sultan Qaboos University Hospital, Sultanate of Oman \\ ${ }^{+}$Department of Mechanical Engineering, University of Bath, Bath, U.K.
}

\section{Corresponding author:}

Dr Michael A. Adams,

Reader in Spine Biomechanics,

Department of Anatomy,

University of Bristol,

Southwell Street,

Bristol BS2 8EJ, U.K.

M.A.Adams@bris.ac.uk

Tel: +44 (0) 1179288363

Fax: +44 (0) 1179254794

KEY WORDS: osteophyte; vertebra; adaptive remodeling; mechanics; BMD. 


\begin{abstract}
Study Design. Mechanical testing of cadaveric spines.
\end{abstract}

Objective. To determine if vertebral body osteophytes act primarily to reduce compressive stress on the intervertebral discs, or to stabilise the spine in bending.

Summary of Background Data. The mechanical significance of vertebral osteophytes is unclear.

Methods. Thoracolumbar spines were obtained from cadavers, aged 51-92 yrs, with vertebral body osteophytes, mostly antero-lateral. Twenty motion segments, from T5-6 to L3-4, were loaded in compression to $1.5 \mathrm{kN}$, and then in flexion, extension, and lateral bending to $10-25 \mathrm{Nm}$ (depending on specimen size) with a compressive preload. Vertebral movements were tracked using an optical 2D MacReflex system. Tests were performed in random order, and were repeated following excision of all osteophytes. Osteophyte function was inferred from a) changes in the force or $\underline{\text { moment resisted, and b) changes in tangent stiffness, measured at maximum displacement or }}$ rotation angle. Volumetric bone mineral density (BMD) was measured using DXA and water immersion. Results were analysed using repeated measures ANOVA.

Results. Resistance to compression was reduced by an average $17 \%$ following osteophyte removal $(\mathrm{p}<0.05)$, and resistance to bending moment in flexion, extension and left and right lateral bending was reduced by 49\%, 36\%, 36\% and 35\% respectively (all p<0.01). Changes in tangent stiffness were similar. Osteophyte removal increased the neutral zone in bending $(p<0.05)$, and on average reduced motion segment BMD by 7-9\%. Results were insensitive to applied loads and moments, but several changes were proportional to osteophyte size.

Conclusions. Vertebral body osteophytes resist bending movements more than compression. Because they reverse the instability in bending that can stimulate their formation, these osteophytes appear to be adaptive rather than degenerative. Results suggest that osteophytes could cause clinical BMD measurements to underestimate vertebral compressive strength. 


\section{Key Points}

1. Experiments on cadaveric thoracolumbar spines showed that removal of vertebral body osteophytes reduced motion segment resistance to compression by $17 \%$, and resistance to bending moment by $35-49 \%$.

2. Results suggest that vertebral body osteophytes primarily stabilize the spine in bending.

3. Osteophytes contribute only 7-9\% of the BMD measurement for a motion segment, but they increase by $17 \%$ its ability to resist compression. This suggests that clinical BMD measurements will systematically underestimate vertebral compressive strength if osteophytes are present. 


\section{Précis}

Experiments on cadaveric thoracolumbar motion segments showed that vertebral body osteophytes resist an average $17 \%$ of applied compressive loading, but $35-49 \%$ of applied bending moments. Osteophyte growth can be stimulated by excessive bending movements, so their formation appears to be adaptive rather than degenerative. 


\section{Introduction}

Substantial osteophytes can be found on at least one vertebral body in 25\% of spines aged 20-29 yrs, and in $90 \%$ of spines aged over 60 yrs. ${ }^{1}$ They tend to be especially large on the antero-lateral margins, and are most common at lower cervical, lower thoracic, and mid-lumbar levels. ${ }^{1,2}$ The word osteophyte ("bone-plant") graphically portrays the branching microstructure of these osteocartilaginous outgrowths (Figure 1). Vertebral osteophytes typically grow by $4 \%$ per year in middle aged women. ${ }^{3}$

The mechanical significance of vertebral body osteophytes is unclear, although their occasional involvement in nerve entrapment syndromes ${ }^{1}$ encourages clinicians to treat them as a degenerative condition, 2,4 sometimes grouped under the term "spondylosis". They have been sub-divided into "traction" and "claw" spurs, ${ }^{5}$ although these can co-exist on the same vertebra ${ }^{4}$ and may simply represent early and late stages in a single process. ${ }^{1}$ Osteophytes are associated with high compressive load-bearing by the spine ${ }^{2,6}$, with male gender, ${ }^{1,2}$ with intervertebral disc degeneration $^{2,3,7,8}$ (though the association is not strong in elderly women ${ }^{9}$ ), and with Schmorl's nodes $^{10}$ and endplate sclerosis ${ }^{8}$. There is a weak association with back pain. ${ }^{2,11}$ Animal experiments have shown that scalpel-induced disc degeneration causes osteophtyes to grow in adjacent vertebrae. ${ }^{12}$ This same experiment concluded that osteophytes arise from proliferating annulus tissue which undergoes metaplasia into hyaline cartilage, and then ossifies in a manner similar to endochondral ossification in growth plates. Endochondral ossification has also been implicated in osteophyte formation at other skeletal sites. ${ }^{13}$ Previous theories (summarised by Nathan $^{1}$ ) suggested that vertebral osteophytes can arise from various tissues, including longitudinal ligaments and periosteum. Certainly, surgical disruption of these latter tissues in animals leads to rapid osteophyte growth on the underlying vertebra. ${ }^{14}$

Osteophytes can, however, be viewed in a more positive light. Bone growth in adults follows the principles of mechanically-adaptive remodelling, in which increases or decreases in stress cause alterations in bone strain (deformation) which are detected by osteocytes. ${ }^{15}$ Osteoclasts and osteoblasts then remove or deposit bone until strain returns to normal levels. ${ }^{16}$ This negative feedback arrangement is influenced by various factors, including a genetic predisposition to lay down more or less bone than normal, ${ }^{17}$ and altered hormone levels which can stimulate formation or loss of bone, for example in women after the menopause. Nevertheless, the main purpose of new bone formation is to reduce excessive bone strain to normal levels. In the case of vertebral body osteophytes, this could be achieved by effectively increasing the cross-sectional area of the vertebral 
body/disc unit, hence reducing the average compressive stress (force per unit area) acting on it.

This could explain why vertebral osteophytes are associated with large body weight and high overall vertebral bone mineral density (BMD) $)^{9,18}$ and why they usually appear on the concave side of spinal curves, where the assumed compressive stresses are greatest. ${ }^{1}$ Similarly, associations between early osteophyte formation and spinal instability could be explained by osteophytes forming in order to reduce movements and hence restore stability to a degenerated spinal level. ${ }^{19}$ Eventual restabilisation could explain why only small developing osteophytes (sometimes characterised as traction spurs) are associated with instability. ${ }^{5}$

Whether osteophytes should be viewed as degeneration or adaptation depends on their mechanical function, and this is currently unknown. The present cadaveric experiment aims to quantify the function of vertebral body osteophytes in resisting bending and compression, in order to increase our understanding of their mechanical significance in the ageing spine. We also compare osteophyte function with measures of BMD, because BMD is often used to predict mechanical vulnerability in an ageing spine.

\section{Materials and Methods}

Cadaveric material. Human thoraco-lumbar spines were removed within 72 hours of death from 11 cadavers (6 male, 5 female) aged 51-92 yrs (mean 77 yrs) which had radiographic evidence of vertebral body osteophytes. None of the subjects had died from a condition known to affect bone metabolism, or had experienced prolonged bed rest prior to death. Most osteophytes were anterolateral, but some vertebrae had posterior osteophytes as well. Their length was measured from radiographs as shown in Figure 2, and an outgrowth was recognized as an osteophyte if its length exceeded $2 \mathrm{~mm}$. The maximum length of any osteophyte from each motion segment was recorded. Spines were dissected into 20 "motion segments" (Table 1) consisting of two vertebrae and the intervening disc and ligaments, and subsequently stored at $-20^{\circ} \mathrm{C}$. All spinal levels between T5-T6 and L3-L4 were represented. All of the discs were degeneration grade 3 or more on a scale of 1-5 20. Accordingly, grade of degeneration had little predictive value in the present experiment, and will not be considered further. Polythene film was used to minimise water loss from specimens during subsequent testing ${ }^{21}$.

Mechanical testing apparatus Each motion segment was secured in two cups of dental plaster so that compressive loading could be applied evenly to its outer surfaces. Loading was applied by a hydraulic materials testing machine (Dartec-Zwick-Roell, Stourbridge, U.K.). Two low-friction 
rollers of variable height (Figure 3) allowed compression to be applied to a specimen maintained at some constant angle of flexion or extension. If one of the rollers was removed, a combination of bending and compression was applied. Because the front roller was positioned approximately 30 $\mathrm{mm}$ anterior to the geometric disc centre, a typical bending moment of $15 \mathrm{Nm}$ could be achieved with a compressive load of $500 \mathrm{~N}$. The use of this apparatus to simulate physiologically-reasonable loading has previously been justified. ${ }^{22}$ An initial period of compressive creep loading ( $300 \mathrm{~N}$ for 15 minutes) was applied in order to reduce post-mortem disc hydration to typical physiological levels. $^{23}$

Resistance to compression Each motion segment was positioned in 2-4 of flexion (depending on specimen mobility) in order to simulate the moderately flattened back typical of manual handling. ${ }^{24}$ A few degrees of flexion is usually sufficient to remove compressive load-bearing from the neural arch, so that all of the load is resisted by the vertebral bodies and intervertebral disc. ${ }^{25}$ The compressive force was then increased to approximately $1.5 \mathrm{kN}$, in a linear-ramp loading-unloading cycle that lasted $5.0 \mathrm{~s}$, with the machine operating in "position-control" for maximum precision. The vertically-acting compressive force acting on the load cell, and the vertical ram displacement (Figure 3), were sampled at $100 \mathrm{~Hz}$ and plotted in real time on the computer monitor.

Resistance to bending With the rear roller removed, a bending moment rising to 10-25 Nm (depending on specimen size and estimated strength) was applied and removed during a $5.0 \mathrm{~s}$ loading-unloading cycle under "position-control". During this time the compressive force typically rose to a peak value of 400-900 N. Vertebral movements were tracked at $50 \mathrm{~Hz}$ using an optical 2D MacReflex system which detected two reflective markers attached to the lateral cortex of each vertebral body and two more to each metal cup. Preliminary checks on each specimen were made to ensure that there was negligible movement between markers on the vertebrae and on the cups. Precision was better than $0.01 \mathrm{~mm}$, errors in flexion/extension angles were less than $5 \%{ }^{22}$ By rotating the upper plate and rollers about a vertical axis, bending tests were repeated in extension, and left and right lateral bending. The order of bending tests was randomized between specimens.

Creep loading Resistance to compression and bending were measured before and after a $2 \mathrm{hr}$ period of compressive creep loading at 1.0-1.5 kN (depending on specimen size). Creep loading expels water from the disc, so that post-creep results are applicable to the in-vivo situation after the $1^{\text {st }}$ few hours of each day ${ }^{23}$. Creep also helps to ensure that subsequent bending moment-rotation graphs have good reproducibility ${ }^{22}$. 
Stress profilometry After creep, distributions of compressive "stress" were measured along the midsagittal diameter of the intervertebral disc using a miniature pressure transducer, side-mounted in a $1.3 \mathrm{~mm}$-diameter needle. ${ }^{26}$ Stress profiles were obtained successfully from only two discs because the presence of osteophytes made the technique difficult, and transducer breakages were common. Removal of osteophytes Tests were repeated following surgical excision of all osteophytes from the motion segment. Cutting was performed using a small saw and scalpel, as indicated in Figure 4. Removal of each bone fragment required an additional horizontal cut along the interface between vertebra and disc. The total volume of osteophytes removed from a given motion segment was measured using a water-displacement technique.

Bone mineral density (BMD) Before mechanical testing, the overall BMD of each motion segment was measured using dual photon X-ray absorptiometry (DXA) using a Piximus machine (Lunar Corporation, Madison, WI, USA) which has previously been calibrated against ash weight. ${ }^{27}$ Measurements were performed with the radiation beam passing laterally through the specimen, and also with the beam passing in the antero-posterior direction, as occurs clinically. Volumetric BMD was measured for the removed osteophytes by scanning all removed fragments from a given motion segment, and then dividing the bone mineral content (BMC) by the total volume of the osteophytes, measured by water immersion.

Statistical analysis Repeated measures ANOVA was used to detect changes in mechanical properties after osteophyte excision. Linear regression was used to examine the influence of age and osteophyte size.

\section{Results}

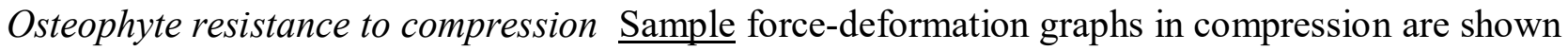
in Figure 5. The graph for the intact specimen before creep loading served as a baseline, although the current paper concerns changes immediately before and after the removal of osteophytes. Osteophyte resistance to compression was analysed in two complementary ways. Firstly, the compressive force resisted at constant displacement (corresponding to a reference force before creep of $1000 \mathrm{~N}$ ) was compared before and after osteophyte removal. For the example in Figure 5, the constant compressive displacement is $0.43 \mathrm{~mm}$, as indicated by the vertical arrow. Osteophyte removal reduced the compressive force resisted by the motion segment, from $790 \mathrm{~N}$ to $610 \mathrm{~N}$, so it can be inferred that the resistance coming from the osteophytes when in-situ was $(790-610)=180$ $\mathrm{N}$, which is $23 \%$ of the resistance from the whole motion segment $(790 \mathrm{~N})$. This is a measure of the 

involved comparing each motion segment's "tangent stiffness", before and after osteophyte removal. For the example in Figure 5, the tangent stiffness was evaluated as the gradient of the force-deformation graph, using 20 data points centered on the reference displacement of $0.43 \mathrm{~mm}$, which corresponds to a force of $1 \mathrm{kN}$. Gradients are represented by oblique dotted lines in Figure 5. Any change in tangent stiffness after osteophyte removal provides a measure of the contribution of the osteophytes to resisting the maximum compressive force $(790 \mathrm{~N})$. This second measure of osteophyte resistance to compression is less sensitive than the first to any slight drift in zero displacement values during the experiment.

Average results are summarized in Table 2 for both methods. Osteophyte removal reduced the motion segments' resistance to compression by an average 17-18\%, depending on which method of analysis was used. High standard deviations probably reflect the varying size of osteophytes.

Resistance to bending Sample bending moment-rotation graphs are shown in Figure 6. Flexion and extension graphs were combined (as were graphs for lateral bending to left and right, which are not shown). Resistance to bending, measured at a reference moment of $5 \mathrm{Nm}$, was assessed using the same two methods as for compression, and average results for both methods are summarized in Table 2. Osteophyte removal reduced motion segment resistance to flexion by an average $49-50 \%$, reduced resistance to extension by $36-42 \%$, and reduced resistance to lateral bending by $35-41 \%$.

Influence of testing conditions on mechanical results Osteophyte resistance to bending was additionally evaluated at a reference moment of $10 \mathrm{Nm}$ in a sub-group of 6 specimens which appeared particularly strong and so were tested to higher moments. In this subgroup, reduction in resistance to flexion following osteophyte removal averaged $61 \%$ (SD $43 \%$ ) at 5Nm, and $64 \%$ (SD $38 \%$ ) at $10 \mathrm{Nm}$. Equivalent values in extension were: $47 \%$ (SD 59\%) at 5Nm, and 47\% (SD 57\%) at $10 \mathrm{Nm}$. The effect of osteophyte removal on resistance to small bending moments was investigated by evaluating the "neutral zone", which was defined as the range of flexion or extension in response to an applied bending moment of $0.5 \mathrm{Nm}$. Osteophyte removal increased the neutral zone in flexion from $1.1^{\circ}\left(\mathrm{SD} 0.8^{\circ}\right)$ to $2.0^{\circ}\left(\mathrm{SD} 1.8^{\circ}\right)$, and in right-sided bending from $2.4^{\circ}\left(\mathrm{SD} 0.8^{\circ}\right)$ to $3.0^{\circ}(\mathrm{SD}$ $\left.1.1^{\circ}\right)$. Both of these increases were significant $(\mathrm{p}<0.05)$. Smaller non-significant increases in neutral zone were observed in extension and left-sided bending after osteophyte removal. Influence of osteophyte size on mechanical results The length of the largest osteophyte removed from each specimen (Figure 2) averaged $7 \mathrm{~mm}$ (range 2-14 mm), and their combined volume 
averaged $1.47 \mathrm{~cm}^{3}$ (SD $1.50 \mathrm{~cm}^{3}$, range $0.2-6.1 \mathrm{~cm}^{3}$ ). The mechanical influence of osteophytes generally increased with these measures of size, although there was considerable scatter. The strongest influence was between total volume (in $\mathrm{cm}^{3}$ ) of removed osteophyte, and decreased stiffness in right side bending $\left(\mathrm{r}^{2}=0.31 \mathrm{p}<0.05\right)$.

Influence of BMD on mechanical results Volumetric BMD of removed osteophytes averaged 0.37 $(\mathrm{SD} 0.15) \mathrm{g} / \mathrm{cm}^{3}$ and did not depend significantly on gender or age. It was a poor predictor of most mechanical outcomes, but was proportional to changes in compressive stiffness $\left(r^{2}=0.34, p=<.05\right)$ and left sided bending $\left(\mathrm{r}^{2}=0.25, \mathrm{p}<0.05\right)$ following osteophyte removal. Removal of all osteophytes reduced the BMD measurement for the whole motion segment by 7\% (SD 5\%) when BMD was measured in the sagittal plane, and by $9 \%$ (SD 13\%) when BMD was measured in the anteroposterior direction.

Stress profilometry In both specimens, osteophyte removal reduced or removed a concentration of compressive stress in the adjacent annulus (Figure 7). These preliminary results are presented to stimulate future studies, perhaps using smaller transducers or mathematical modelling.

\section{Discussion}

Summary of findings Vertebral body osteophytes resisted an average $17 \%$ of spinal compressive loading, and $35-49 \%$ of complex loading in bending and compression. Mechanical influences tended to increase with measures of osteophyte size, but were not sensitive to experimental conditions. Osteophyte removal reduced motion segment BMD by only 7-9\% on average.

Strengths and weaknesses of the study Quantitative assessment of osteophyte function requires human specimens, and it took two years to collect the required 20 motion segments (with osteophytes) from donated human cadavers. A strength of the study is the method of testing, which aims to reproduce physiological-style complex loading as closely as possible, rather than to apply pure moments or forces. Motion segment resistance to bending and compression interact, ${ }^{28-30}$ and few conditions in life would apply one without the other. Postmortem changes have little effect on the elastic mechanical properties of human spines. ${ }^{31,32}$ Osteophyte removal necessitated cutting of some outer annulus fibres (Figure 4), so the observed mechanical effects are attributable to osteophytes and their attachments.

Relationship to other studies There is some experimental evidence that anterior osteophytes resist flexion more strongly than compression. ${ }^{33}$ Cadaveric experiments have shown that disc degeneration leads to increased stress concentrations in the annulus fibrosus ${ }^{26}$ and a finite-element 
model has predicted that this can stimulate osteophyte formation. ${ }^{34}$ Clinical studies of BMD have noted that vertebral body osteophytes are associated with increased vertebral $\mathrm{BMD}^{35}$ and may explain why vertebral BMD often increases with age in men. ${ }^{36}$

Explanation of results The modest role of vertebral osteophytes in resisting compression can be attributed to the relatively high compressive stiffness of the human spine. Increasing the compressive force on a vertebral body-disc-vertebral body specimen from $250 \mathrm{~N}$ (equivalent to lying down) to $3 \mathrm{kN}$ (equivalent to moderate manual labour) compresses the specimen by only 0.55 $-0.94 \mathrm{~mm} .{ }^{37}$ This small vertical deformation would be reduced further by the presence of neural arches, which can resist more than $50 \%$ of the compressive force on the spine when the discs are degenerated and narrowed. ${ }^{38}$ Evidently, small compressive deformations of a fraction of a millimeter are not sufficient to produce substantial forces in vertebral osteophytes, even when they "bridge" adjacent vertebrae. This interpretation is supported by the finding that intra-discal nucleus pressure (which is a good indicator of overall disc compression) is not greatly affected by the presence of osteophytes (Figure 7) or by the presence of a spinal fixator ${ }^{39}$ which would bridge adjacent vertebrae in a similar manner to bridging osteophytes. In both cases, vertical deformation of the mechanical linkage (bridging osteophyte, or instrumentation) is too small to generate much force within it.

None of the specimens in the present study had a complete and rigid anterior bridge of bone, so the influence of osteophytes on load-bearing must have come mainly from their ability to modify the resistance to deformation of the adjacent discs. If a disc is idealized as a circle in the transverse plane, then increasing its radius by $4 \mathrm{~mm}$ would typically increase its cross-sectional area by approximately $50 \%$. Extremely large marginal osteophytes effectively increase disc area by this amount ${ }^{1}$ and appear to remain bonded to the bulging disc; more typically, however, they increase disc area by $10-20 \%$. This could explain why specimen resistance to compression fell by $17 \%$ in the present study when the osteophytes were removed.

The curving shape of many large osteophytes suggests that they also resist radial bulging by the disc. Radial bulging increases when discs lose height and internal pressure, rather in the manner of a flat tyre, ${ }^{40}$ and this could explain why a pharmacological intervention that slows down disc space narrowing also slows down vertebral osteophyte growth. ${ }^{41}$ Radial bulging is greater when the spine is subjected to bending compared to pure compression, ${ }^{42}$ especially at high angles of bending ${ }^{43}$ and this probably explains why osteophytes resist bending more than compression. Disc radial bulging tends to be greatest anteriorly, ${ }^{42}$ especially after endplate fracture and disc decompression ${ }^{44}$ and this 
could explain why osteophytes tend to be larger anteriorly. Particularly high resistance to extension by anterior osteophytes (Table 2) can be explained by assuming the centre of rotation lies posterior to the disc ${ }^{22}$ so that even small angles of extension stretch the calcified and fibrous tissues of the antero-lateral osteophytes.

If osteophytes do indeed represent adaptive remodelling, then they provide an interesting contrast with the generalised osteopaenia observed in most elderly spines. Why should bone be resorbed from vertebral body trabeculae, increasing the risk of osteoporotic fracture, if it is still possible for the vertebra to respond positively to mechanical stimuli by depositing bone in osteophytes? ${ }^{45}$ New osteophyte bone may be denser than the rest of the vertebra ${ }^{1}$ and this is supported by the present study, which reported average volumetric BMD of $0.37 \mathrm{~g} / \mathrm{cm}^{3}$ which is higher than the average values for vertebral bodies of similar age $\left(0.17 \mathrm{~g} / \mathrm{cm}^{3}\right)$ measured previously on the same DXA machine. ${ }^{46}$ Perhaps, the vertebral body margins are subjected to such high concentrations of stress that the resulting strains (deformations) exceed the threshold for bone deposition, even though the average stresses and strains on the vertebral body are much lower, and allow bone resorption ? $^{47}$ High concentrations of compressive stress are applied to the vertebral margins by degenerated discs, ${ }^{26,27}$ and bulging discs will stretch the periosteum so that high tensile strains are generated where it inserts into bone.

Unanswered questions and future research Longitudinal studies on humans, or experiments on animals, are required to prove that motion segment instability is the primary stimulus for osteophyte formation. Similar studies could investigate whether osteophytes reduce in size as the motion segment regains stability following progressive fibrosis in the disc and ligaments.

Clinical implications Segmental instability follows disc degeneration ${ }^{22}$ and appears to stimulate the growth of vertebral body osteophytes. ${ }^{12}$ The present experiment shows that osteophytes act primarily to increase resistance to bending and to reduce the 'neutral zone' in bending. Therefore, osteophytes reverse the very stimulus that causes them to form. In this way, their growth can be viewed as purposeful, or adaptive, rather than degenerative.

A second clinical implication concerns BMD-based predictions of vertebral body compressive strength. The current findings suggest that BMD measurements systematically underestimate vertebral compressive strength if osteophytes are included. This is because the osteophytes contribute only $7-9 \%$ of the BMD measurement for a motion segment, but they increase by $17 \%$ its ability to resist compression. These cadaveric results therefore explain why a recent clinical study 
showed that BMD-based estimates of vertebral fracture risk are improved if "focal artifacts" such as osteophytes are excluded. ${ }^{48}$

Acknowledgements

Research supported in the UK by Action Medical Research and by the Arthritis Research Campaign. 


\section{References}

1. Nathan H. Osteophytes of the vertebral column. An anatomical study of their development according to age, race and sex with considerations as to their etiology and significance. J Bone Joint Surg [Am] 1962;44(243-68).

2. O'Neill TW, McCloskey EV, Kanis JA, et al. The distribution, determinants, and clinical correlates of vertebral osteophytosis: a population based survey. J Rheumatol 1999;26(4):842-8.

3. Hassett G, Hart DJ, Manek NJ, Doyle DV, Spector TD. Risk factors for progression of lumbar spine disc degeneration: the Chingford Study. Arthritis Rheum 2003;48(11):3112-7.

4. Heggeness MH, Doherty BJ. Morphologic study of lumbar vertebral osteophytes. South Med J 1998;91(2):187-9.

5. Macnab I. The traction spur. An indicator of segmental instability. J Bone Joint Surg Am 1971;53(4):663-70.

6. Echarri JJ, Forriol F. Effect of axial load on the cervical spine: a study of Congolese woodbearers. Int Orthop 2002;26(3):141-4.

7. Vernon-Roberts B, Pirie CJ. Degenerative changes in the intervertebral discs of the lumbar spine and their sequelae. Rheumatol Rehabil 1977;16(1):13-21.

8. Pye SR, Reid DM, Adams JE, Silman AJ, O'Neill TW. Radiographic features of lumbar disc degeneration and bone mineral density in men and women. Ann Rheum Dis 2006;65(2):234-8.

9. Oishi Y, Shimizu K, Katoh T, et al. Lack of association between lumbar disc degeneration and osteophyte formation in elderly japanese women with back pain. Bone 2003;32(4):405-11.

10. Pfirrmann CW, Resnick D. Schmorl nodes of the thoracic and lumbar spine: radiographicpathologic study of prevalence, characterization, and correlation with degenerative changes of 1,650 spinal levels in 100 cadavers. Radiology 2001;219(2):368-74.

11. van Tulder MW, Assendelft WJ, Koes BW, Bouter LM. Spinal radiographic findings and nonspecific low back pain. A systematic review of observational studies. Spine 1997;22(4):427-34.

12. Lipson SJ, Muir H. Vertebral osteophyte formation in experimental disc degeneration. Morphologic and proteoglycan changes over time. Arthritis Rheum 1980;23(3):319-24.

13. Hashimoto S, Creighton-Achermann L, Takahashi K, Amiel D, Coutts RD, Lotz M. Development and regulation of osteophyte formation during experimental osteoarthritis. Osteoarthritis Cartilage 2002;10(3):180-7.

14. Ledet EH, Jeshuran W, Glennon JC, et al. Small intestinal submucosa for anular defect closure: long-term response in an in vivo sheep model. Spine (Phila Pa 1976) 2009;34(14):1457-63.

15. Frost HM. On our age-related bone loss: insights from a new paradigm. J Bone Miner Res 1997;12(10):1539-46.

16. Goodship AE, Lanyon LE, McFie H. Functional adaptation of bone to increased stress. An experimental study. J Bone Joint Surg [Am] 1979;61(4):539-46.

17. Weinfeld RM, Olson PN, Maki DD, Griffiths HJ. The prevalence of diffuse idiopathic skeletal hyperostosis (DISH) in two large American Midwest metropolitan hospital populations. Skeletal Radiol 1997;26(4):222-5. 
18. Miyakoshi N, Itoi E, Murai H, Wakabayashi I, Ito H, Minato T. Inverse relation between osteoporosis and spondylosis in postmenopausal women as evaluated by bone mineral density and semiquantitative scoring of spinal degeneration. Spine 2003;28(5):492-5.

19. Kirkaldy-Willis WH, Farfan HF. Instability of the lumbar spine. Clin Orthop 1982(165):11023.

20. Adams MA, Dolan P, Hutton WC. The stages of disc degeneration as revealed by discograms. J Bone Joint Surg [Br] 1986;68(1):36-41.

21. Pollintine P, Luo J, Offa-Jones B, Dolan P, Adams MA. Bone creep can cause progressive vertebral deformity. Bone 2009;45(3):466-72.

22. Zhao F, Pollintine P, Hole BD, Dolan P, Adams MA. Discogenic origins of spinal instability. Spine 2005;30(23):2621-30.

23. McMillan DW, Garbutt G, Adams MA. Effect of sustained loading on the water content of intervertebral discs: implications for disc metabolism. Ann Rheum Dis 1996;55(12):880-7.

24. Dolan P, Earley M, Adams MA. Bending and compressive stresses acting on the lumbar spine during lifting activities. J Biomech 1994;27(10):1237-48.

25. Adams MA, Hutton WC. The effect of posture on the role of the apophysial joints in resisting intervertebral compressive forces. J Bone Joint Surg [Br] 1980;62(3):358-62.

26. Adams MA, McNally DS, Dolan P. 'Stress' distributions inside intervertebral discs. The effects of age and degeneration. J Bone Joint Surg Br 1996;78(6):965-72.

27. Adams MA, Pollintine P, Tobias JH, Wakley GK, Dolan P. Intervertebral disc degeneration can predispose to anterior vertebral fractures in the thoracolumbar spine. J Bone Miner Res 2006;21(9):1409-16.

28. Adams MA, Dolan P. A technique for quantifying the bending moment acting on the lumbar spine in vivo. J Biomech 1991;24(2):117-26.

29. Janevic J, Ashton-Miller JA, Schultz AB. Large compressive preloads decrease lumbar motion segment flexibility. J Orthop Res 1991;9(2):228-36.

30. Gardner-Morse MG, Stokes IA. Physiological axial compressive preloads increase motion segment stiffness, linearity and hysteresis in all six degrees of freedom for small displacements about the neutral posture. J Orthop Res 2003;21(3):547-52.

31. Adams MA, Bogduk N, Burton K, Dolan P. The Biomechanics of Back Pain. (2nd Edition). Churchill Livingstone, Edinburgh; 2006.

32. Dhillon N, Bass EC, Lotz JC. Effect of frozen storage on the creep behavior of human intervertebral discs. Spine 2001;26(8):883-8.

33. Toh E, Yerby SA, Bay BK, McLain RF, Benson DR, Mochida J. The effect of anterior osteophytes and flexural position on thoracic trabecular strain. Spine 2001;26(1):22-6.

34. Kumaresan S, Yoganandan N, Pintar FA, Maiman DJ, Goel VK. Contribution of disc degeneration to osteophyte formation in the cervical spine: a biomechanical investigation. J Orthop Res 2001;19(5):977-84.

35. $\mathrm{Yu} \mathrm{W}$, Gluer $\mathrm{CC}$, Fuerst $\mathrm{T}$, et al. Influence of degenerative joint disease on spinal bone mineral measurements in postmenopausal women. Calcif Tissue Int 1995;57(3):169-74. 
36. Zmuda JM, Cauley JA, Glynn NW, Finkelstein JS. Posterior-anterior and lateral dual-energy $\mathrm{X}$-ray absorptiometry for the assessment of vertebral osteoporosis and bone loss among older men. J Bone Miner Res 2000;15(7):1417-24.

37. Brinckmann P, Frobin W, Hierholzer E, Horst M. Deformation of the vertebral end-plate under axial loading of the spine. Spine 1983;8(8):851-6.

38. Pollintine P, Przybyla AS, Dolan P, Adams MA. Neural arch load-bearing in old and degenerated spines. J Biomech 2004;37(2):197-204.

39. Edwards AG, McNally DS, Mulholland RC, Goodship AE. The effects of posterior fixation on internal intervertebral disc mechanics. J Bone Joint Surg Br 1997;79(1):154-60.

40. Brinckmann P, Grootenboer H. Change of disc height, radial disc bulge, and intradiscal pressure from discectomy. An in vitro investigation on human lumbar discs. Spine 1991;16(6):6416.

41. Neogi T, Nevitt MC, Ensrud KE, Bauer D, Felson DT. The effect of alendronate on progression of spinal osteophytes and disc-space narrowing. Ann Rheum Dis 2008;67(10):1427-30.

42. Lin HS, Liu YK, Adams KH. Mechanical response of the lumbar intervertebral joint under physiological (complex) loading. J Bone Joint Surg [Am] 1978;60(1):41-55.

43. Stokes IA. Bulging of lumbar intervertebral discs: non-contacting measurements of anatomical specimens. J Spinal Disord 1988;1(3):189-93.

44. Brinckmann P, Horst M. The influence of vertebral body fracture, intradiscal injection, and partial discectomy on the radial bulge and height of human lumbar discs. Spine 1985;10(2):138-45.

45. Ito M, Hayashi K, Yamada M, Uetani M, Nakamura T. Relationship of osteophytes to bone mineral density and spinal fracture in men. Radiology 1993;189(2):497-502.

46. Luo J, Skrzypiec DM, Pollintine P, Adams MA, Annesley-Williams DJ, Dolan P.

Mechanical efficacy of vertebroplasty: Influence of cement type, BMD, fracture severity, and disc degeneration. Bone 2007;40(4):1110-9.

47. Frost HM. Bone "mass" and the "mechanostat": a proposal. Anat Rec 1987;219(1):1-9.

48. Tsang JF, Leslie WD. Exclusion of focal vertebral artifacts from spine bone densitometry and fracture prediction: a comparison of expert physicians, three computer algorithms, and the minimum vertebra. J Bone Miner Res 2007;22(6):789-98. 
Table 1 Details of 20 motion segments tested from 11 cadaveric spines.

\begin{tabular}{|l|l|l|l|}
\hline Gender & Age $(\mathrm{yrs})$ & Motion segments & $\mathrm{n}$ \\
\hline $\mathrm{F}$ & 51 & $\mathrm{~T} 6-\mathrm{T} 7$ / T8-T9 & 2 \\
\hline $\mathrm{F}$ & 67 & $\mathrm{~T} 5-\mathrm{T} 6$ / T7-T8/ T10-T11 & 3 \\
\hline $\mathrm{M}$ & 84 & L1-L2 & 1 \\
\hline $\mathrm{M}$ & 74 & T7-T8 / T9-T10 & 2 \\
\hline $\mathrm{F}$ & 90 & T8-T9 / T10-T11/ L1-L2/ L3-/4 & 4 \\
\hline $\mathrm{F}$ & 76 & T8-T9 & 1 \\
\hline $\mathrm{F}$ & 92 & T5-T6 & 1 \\
\hline M & 82 & T8-T9 / T11-T12 & 2 \\
\hline M & 82 & T12-L1 /T10-T11 & 2 \\
\hline M & 82 & T9-T10 & 1 \\
\hline M & 72 & T6-T7 & 1 \\
\hline Total number of motion segments & 20 \\
\hline
\end{tabular}

Table 2 Changes in resistance to loading following osteophyte removal. Units of resistance to compression and bending are $\mathrm{N}$, and $\mathrm{Nm}$, respectively. Units of tangent stiffness are $\mathrm{N} / \mathrm{mm}$ and $\mathrm{Nm} /$ deg respectively. Values represent the mean (standard deviation). Changes after osteophyte removal (AOR) are given as a \%: all are significant $(* \mathrm{p}<0.05, * * \mathrm{p}<0.01)$.

\begin{tabular}{|l|l|l|l|l|l|l|}
\hline & \multicolumn{3}{|l|}{ Resistance at constant displ./angle } & \multicolumn{3}{l|}{ Stiffness at constant displ./angle } \\
\hline & Intact & AOR & $\%$ change & Intact & AOR & \% change \\
\hline Compression & 803 & 664 & -17 & 2907 & 2406 & -18 \\
& $(203)$ & $(223)$ & $(22)^{\star}$ & $(997)$ & $(1081)$ & $(22)^{\star}$ \\
\hline Flexion & 4.02 & 1.70 & -49 & 4.15 & 1.67 & -50 \\
& $(3.18)$ & $(1.54)$ & $(39)^{\star *}$ & $(3.51)$ & $(1.72)$ & $(39)^{\star *}$ \\
\hline Extension & 4.62 & 3.02 & -36 & 5.86 & 1.25 & -42 \\
& $(3.50)$ & $(3.72)$ & $(51)^{\star *}$ & $(9.21)$ & $(1.02)$ & $(52)^{\star *}$ \\
\hline R. lateral bend & 2.91 & 1.76 & -35 & 2.24 & 1.15 & -41 \\
& $(1.57)$ & $(1.23)$ & $(42)^{* *}$ & $(1.68)$ & $(0.96)$ & $(34)^{* *}$ \\
\hline L. lateral bend & 2.91 & 1.65 & -36 & 2.03 & 1.17 & -39 \\
& $(1.66)$ & $(1.35)$ & $(46)^{\star *}$ & $(1.63)$ & $(1.05)$ & $(32)^{\star *}$ \\
\hline
\end{tabular}




\section{Figure Legends}

Figure 1 Micro-radiograph of a $2 \mathrm{~mm}$-thick section through a lumbar vertebral body, in the plane of the pedicle. There is a large antero-lateral osteophyte on the lower anterior margin, and smaller ones above and posteriorly. Note the concave upper endplate, which is indicative of osteopaenia. (Reproduced from Adams et al. ${ }^{31}$ with permission of the publisher.)

Figure 2 Diagram of a vertebral body, anterior on left. The size of each osteophyte was calculated from sagittal-plane radiographs as the difference between the length of the line (8-3) and the line (13). The maximum size of any osteophyte on each motion segment was recorded.

Figure 3 Apparatus used to apply compression and bending to each motion segment. The height of the posterior roller (on the right) could be adjusted to enable the specimen to be compressed while positioned in flexion or extension. Removal of one roller enabled the specimen to be tested in combined compression and bending. In stress profilometry, a pressure transducer was pulled through the loaded disc as shown.

Figure 4 Micro-radiograph of a 2 mm-thick mid-sagittal section through a lumbar vertebral body, showing two large anterior osteophytes. Osteophytes were surgically removed by cutting along the direction of the two arrows using a small saw, and then making horizontal cuts with a scalpel. This specimen also shows a Schmorl's node in its upper endplate. (Reproduced from Adams et al. ${ }^{31}$ with permission of the publisher.)

Figure 5 Compressive stiffness graphs for a typical motion segment, before creep (BC), after creep (AC) and after osteophyte removal (AOR). Resistance to compression (in N) was measured at the three points marked, at a constant displacement corresponding to an initial compressive force of 1000 N. Tangent stiffness (gradient of each graph) was measured (in N/mm) at the same three points. This specimen required a load of approx $100 \mathrm{~N}$ to flex the motion segment by $2-4$ degrees, primarily against the resistance of intervertebral ligaments.

Figure 6 Bending stiffness graphs for a typical motion segment, before creep (BC), after creep (AC) and after osteophyte removal (AOR). Responses in flexion and extension have been combined in the same graph. Resistance to flexion (in Nm) was measured at the three points marked, at a constant rotation angle corresponding to an applied moment of $5 \mathrm{Nm}$. Tangent stiffness (gradient of each graph) was measured (in $\mathrm{Nm} / \mathrm{deg}$ ) at the same three points.

Figure 7 Distribution of vertically-acting compressive stress measured across the sagital mid-line of an intervertebral disc, before creep (BC), after creep (AC) and after osteophyte removal (AOR). 
(Anterior on right.) In this example, osteophyte removal appears to have reduced the peak compressive stress in the adjacent annulus. $\mathrm{F}_{\mathrm{N}}=$ functional nucleus; IDP $=$ intradiscal pressure. 
Figures ( TIFF, EPS, or PPT only)

\section{Figure 1}

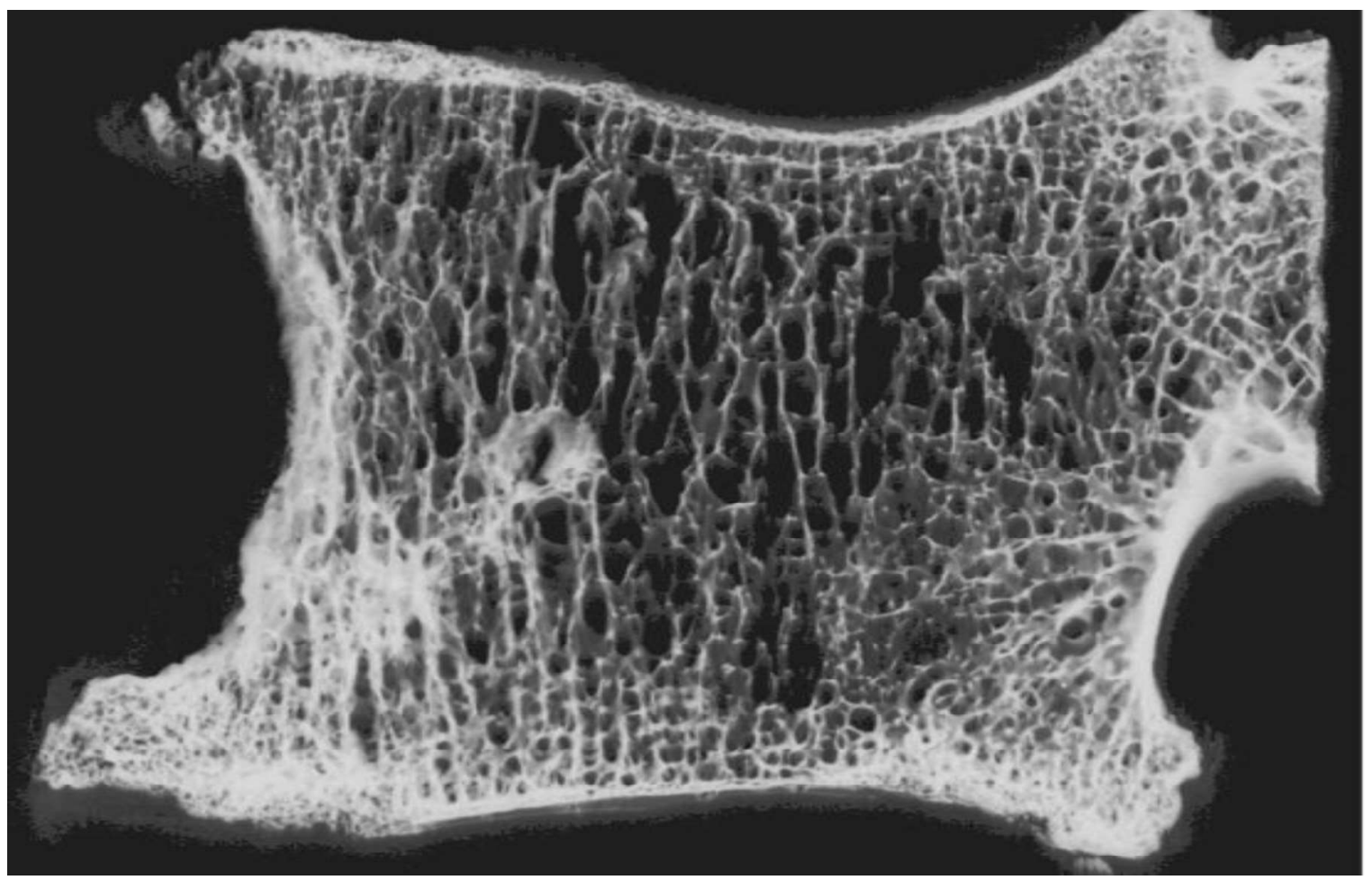

Figure 2

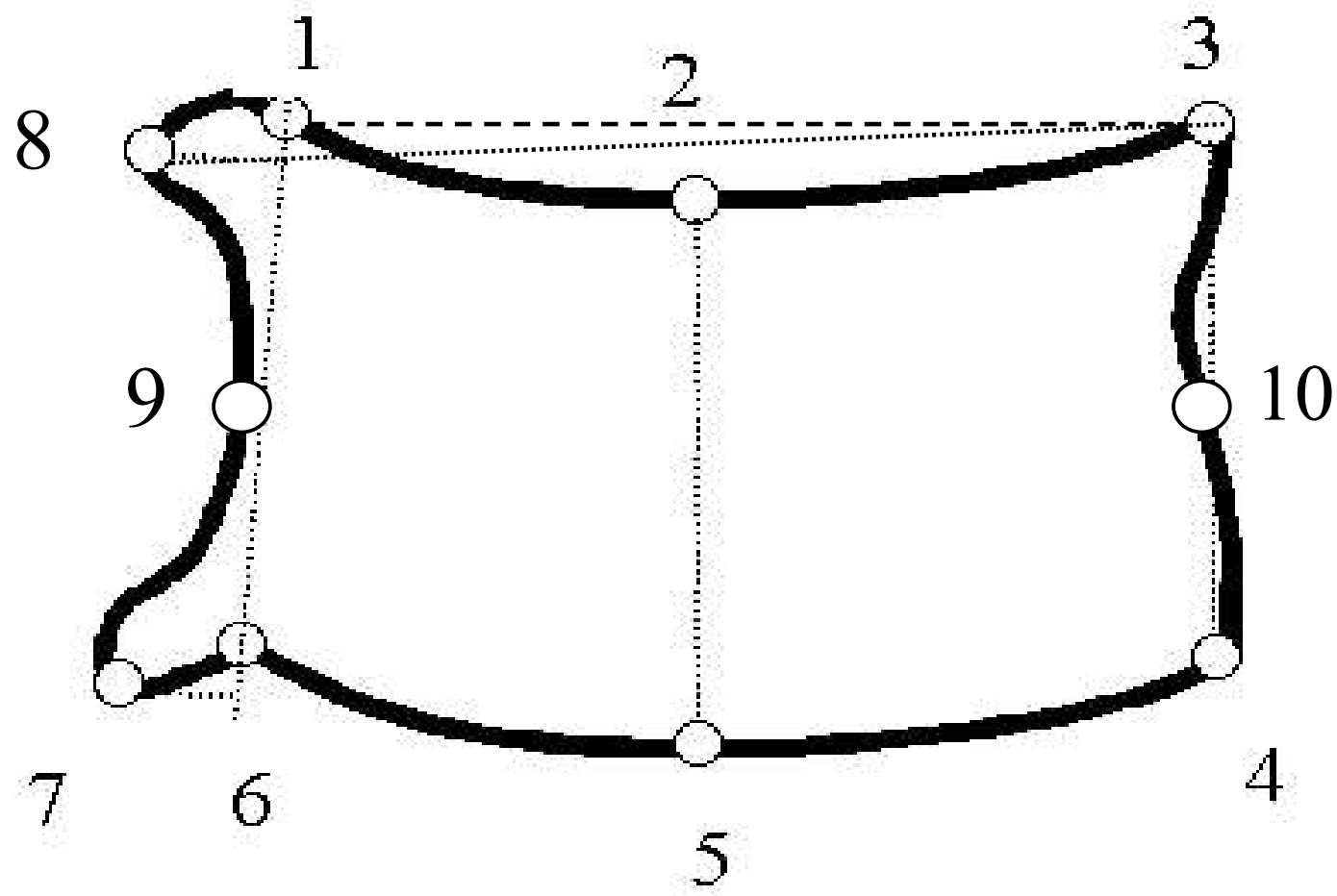




\section{Figure 3}

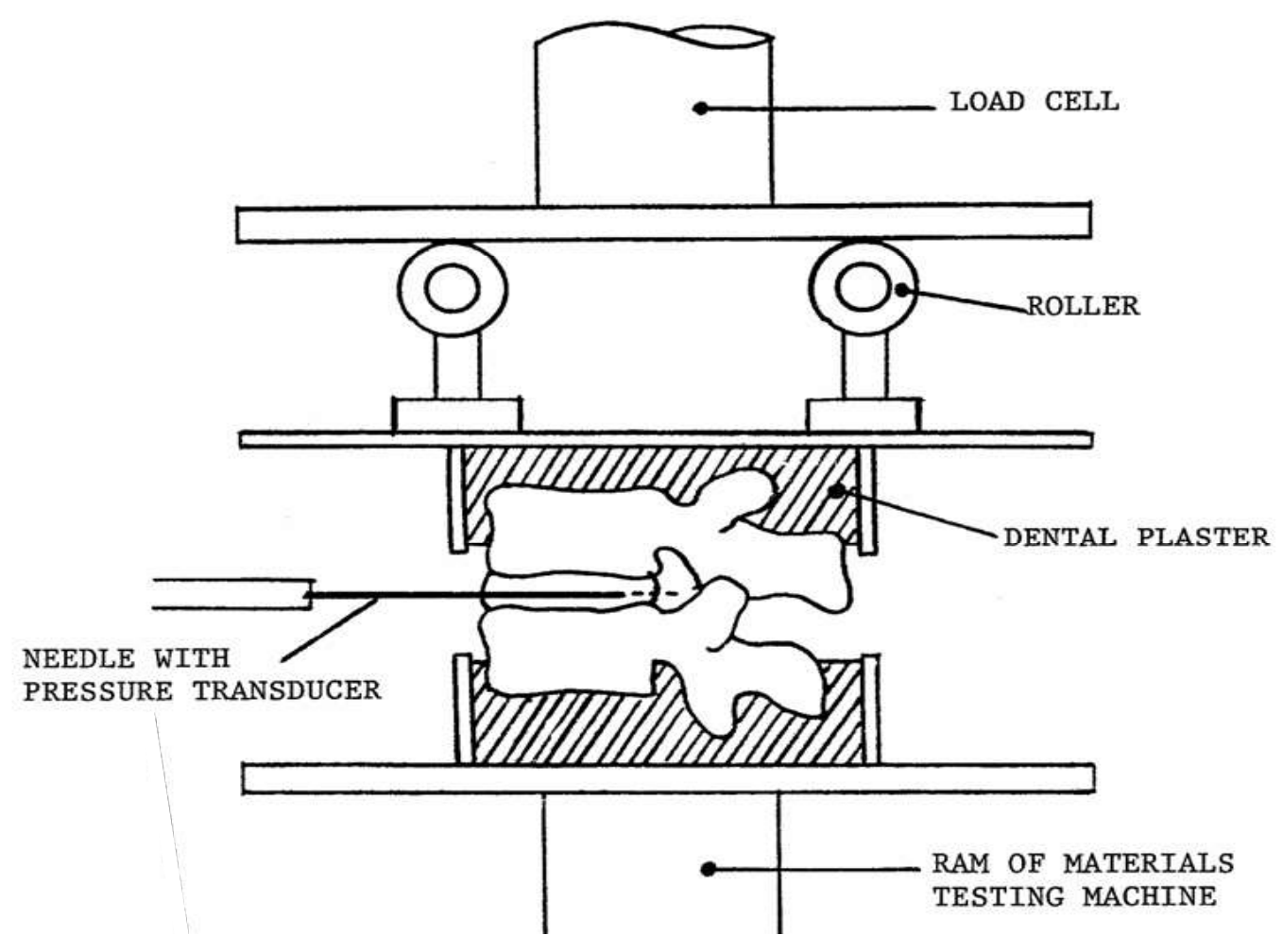

\section{Figure 4}

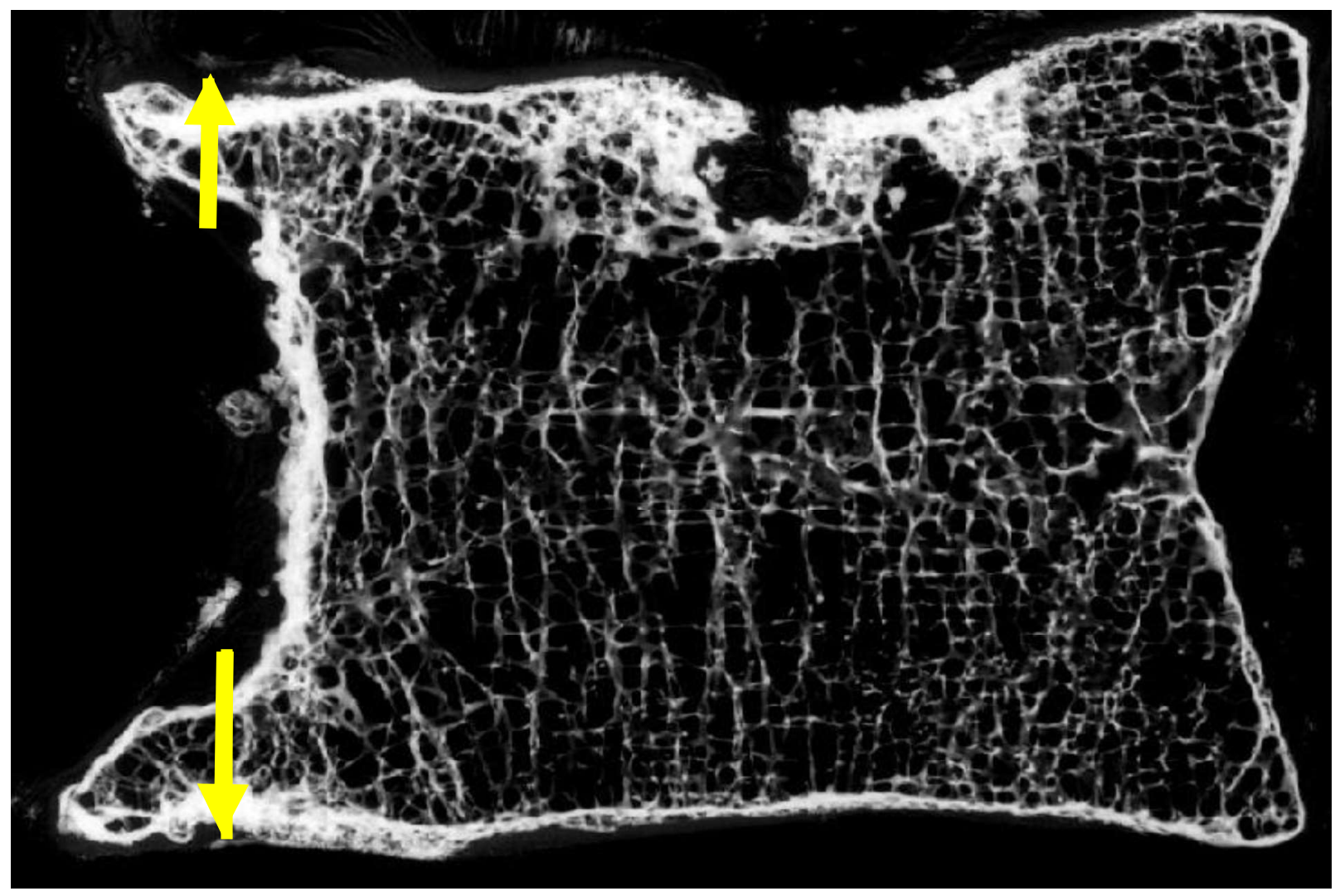


Figure 5

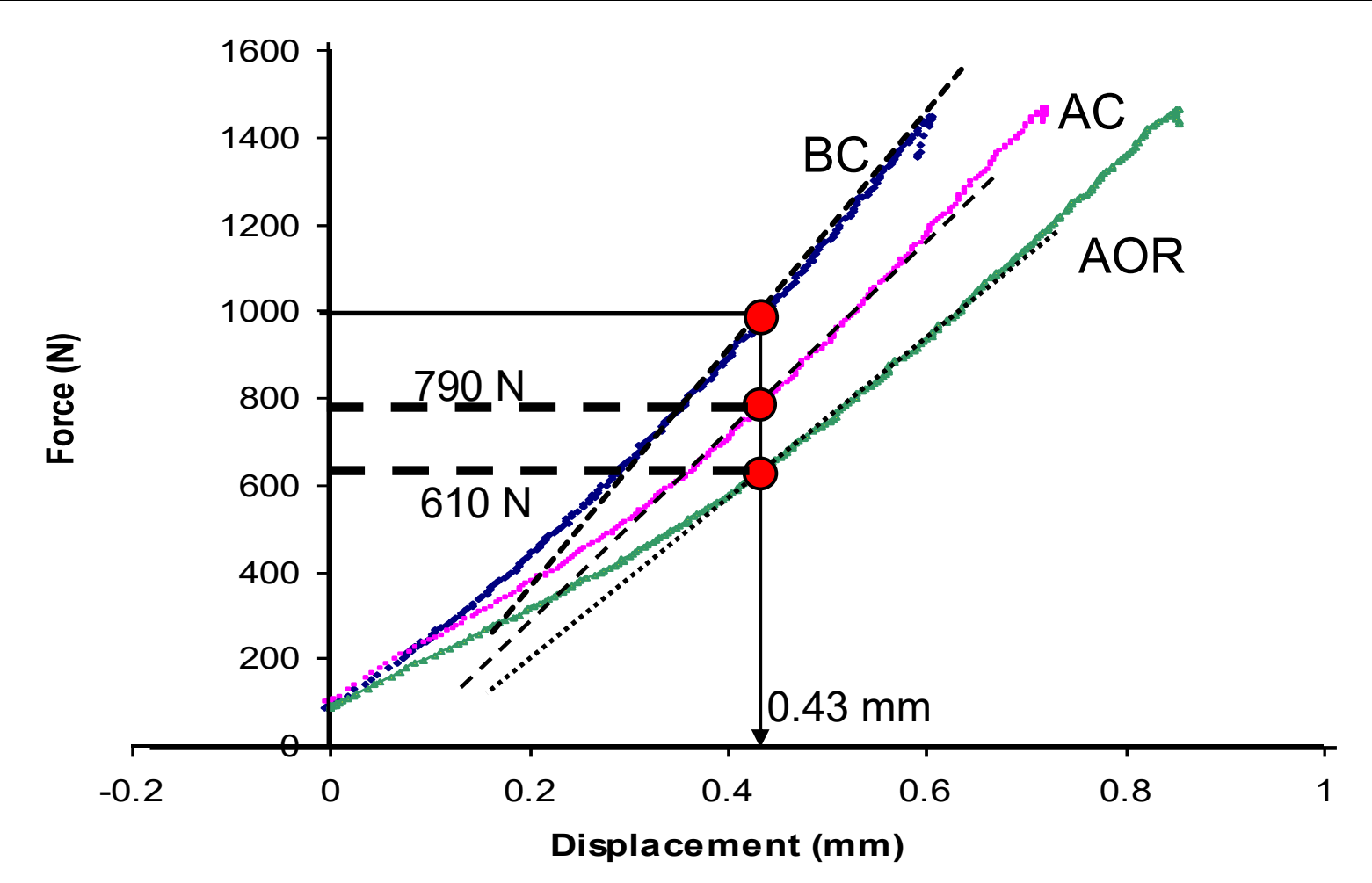

Figure 6

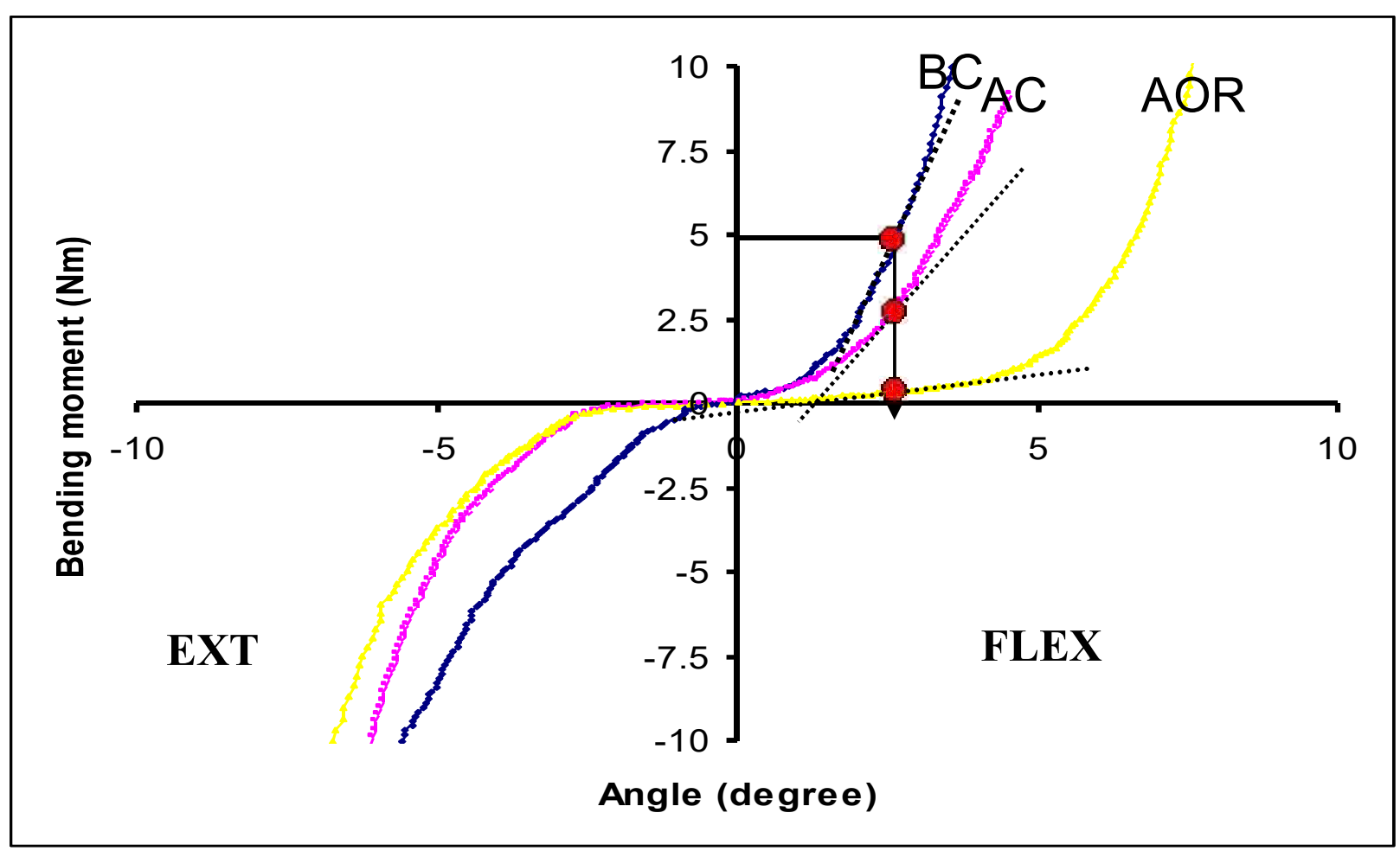


Figure 7

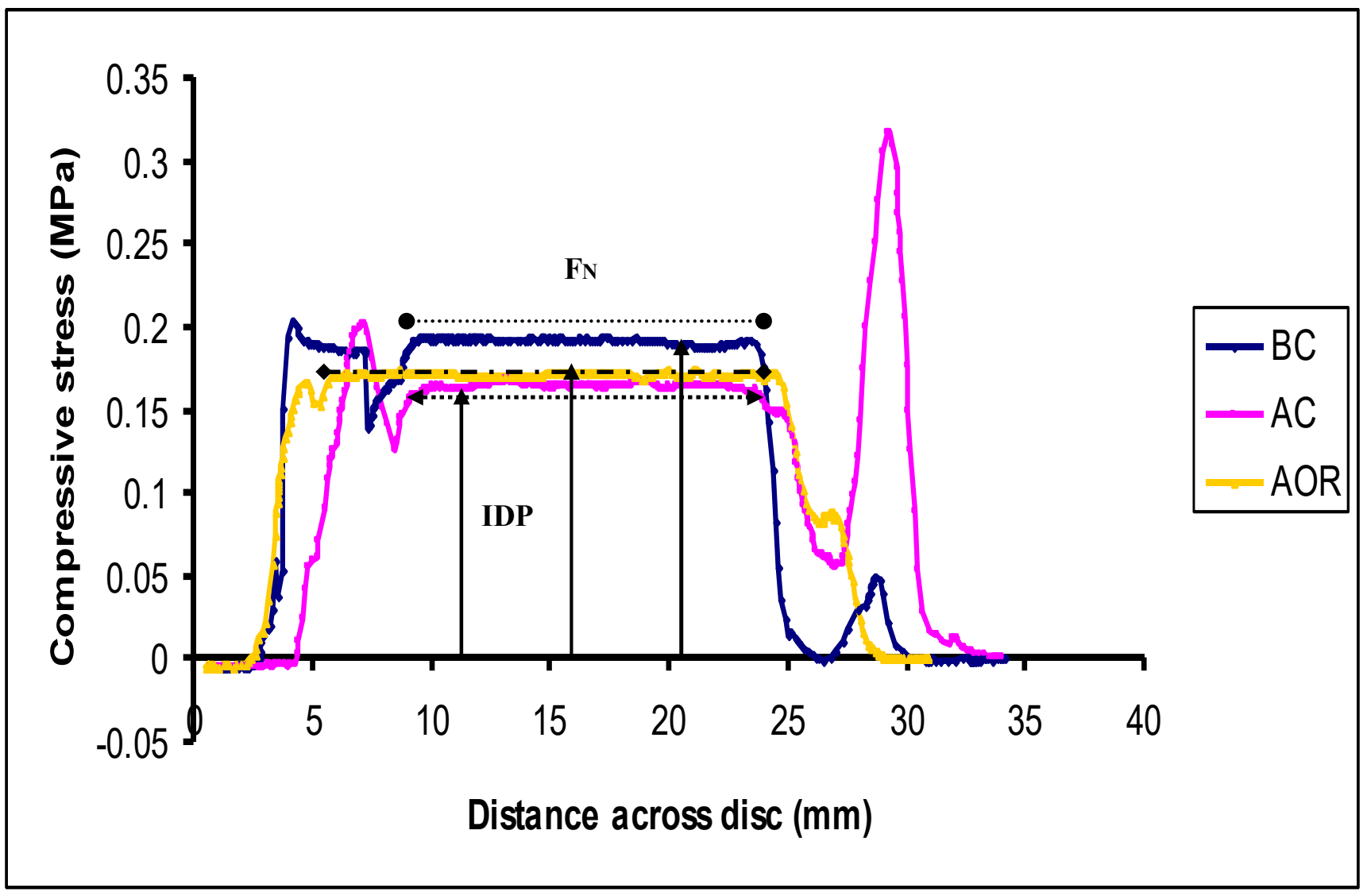

